\title{
Transport infrastructures assessment using multiple GPR configurations and FWD
}

\author{
Vânia Marecos $^{1,2^{*}}$, Simona Fontul ${ }^{1}$, Mercedes Solla ${ }^{3,4}$, and Maria de Lurdes Antunes ${ }^{5}$ \\ ${ }^{1}$ National Laboratory for Civil Engineering, Transportation Department, 1700-066 Lisbon, Portugal \\ ${ }^{2}$ University of Vigo, Doctoral Programme in Geotechnologies applied to Construction, Energy \& \\ Industry, 36310 Vigo, Spain \\ ${ }^{3}$ Spanish Naval Academy, Defense University Center, 36920 Marín, Pontevedra, Spain \\ ${ }^{4}$ University of Vigo, Applied Geotechnologies Research Group, 36310 Vigo, Spain \\ ${ }^{5}$ National Laboratory for Civil Engineering, Board of Directors, 1700-066 Lisbon, Portugal
}

\begin{abstract}
This article presents a case study where FWD and GPR, two NDT methods, were combined to assess the bearing capacity of a flexible pavement. The thickness of the bituminous layer was estimated using a coreless GPR approach: the Common Mid-Point method with Air-Coupled antennas, by combining multiple GPR offset configurations.
\end{abstract}

\section{Introduction}

Transport infrastructures assessment is an important activity that has high social-economic impact and increasing demands. As the construction of new infrastructure decreases it is necessary to continuously evaluate the existing infrastructures in order to plan and optimize its maintenance. This article presents a case study where Falling Weight Deflectometer (FWD) and Ground Penetrating Radar (GPR), two Non-Destructive Testing (NDT) methods, were combined to assess the bearing capacity of a flexible pavement.

FWD is considered the most effective NDT device for pavement deflection measurements worldwide [1-3]. It simulates the pavement responses under traffic loading [4] by applying an impulse load and measuring the pavement deflection bowl (see Figure 1). The layer modulus can be estimated throughout back-calculation using the deflection values measured by the FWD and the layer thickness.

GPR represents one of the most versatile tools for obtaining continuous data along the road, as it operates at traffic speed. It has been used mainly for layer thickness measurement [5]. The most common GPR systems apply an electromagnetic wave at a selected frequency, similar to a sinusoidal wave that propagates vertically through the various layers being reflected at layers interfaces [6-8] (see Figure 4).

The reliability of the estimated pavement moduli depends on the accuracy of layers thickness, this is particularly relevant for bound layers. In this case study the thickness of the bituminous layer was estimated using a coreless GPR approach: the Common Mid-Point method with Air-Coupled antennas (CMP-AC) [9], by combining multiple GPR offset configurations.

\footnotetext{
* Corresponding author: vmarecos@lnec.pt
} 


\section{Case Study}

\subsection{Pavement structure}

The case study was performed on a section of $4.4 \mathrm{~km}$ of a motorway, with one lane in each direction. The flexible pavement structure consists of bituminous layers with a total thickness of $0.125 \mathrm{~m}$ (Zone I Pk 0+000 - 1+1900) or $0.135 \mathrm{~m}$ (Zone II Pk 1+900-4+400) and, beneath, an unbound layer of $0.20 \mathrm{~m}$.

\subsection{FWD load tests}

The FWD load tests were performed along the exterior wheel paths of the lanes (Figure 1 left), according to ASTM D 4695 [10]. The spacing between FWD test points was $100 \mathrm{~m}$.

A nominal $65 \mathrm{kN}$ impulse load was applied over $0.30 \mathrm{~m}$ diameter loading plate and the deflections of the pavement were measured by 9 geophones located at $0,0.30,0.45,0.60$, $0.90,1.20,1.50,1.80$ and $2.10 \mathrm{~m}$ (which correspond to the designated deflections $\mathrm{D}_{0}, \mathrm{D}_{1}, \mathrm{D}_{2}$, $\mathrm{D}_{3}, \mathrm{D}_{4}, \mathrm{D}_{5}, \mathrm{D}_{6}, \mathrm{D}_{7}$, and $\mathrm{D}_{8}$ ) from the centre of the loading plate (Figure 1 right). The surface temperature of the pavement during the tests was also measured.
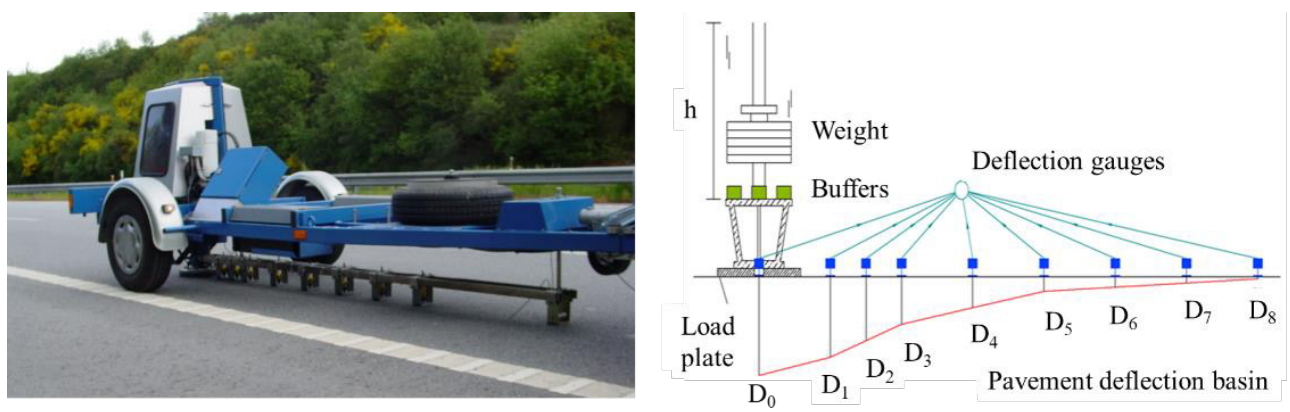

Figure 1. FWD during the tests (left) and schematic representation of FWD load test (right).

Figure 2 presents the normalized deflections measured with the FWD along the exterior wheel path in the West-East direction.

To apply the methodology developed by the authors: the CMP-AC [9], in this study, two points, with the same design thickness and different structural behaviour, were selected. Figure 3 shows the deflection basins for the selected points: pk $0+000$ and pk $0+200$ in the West-East direction.

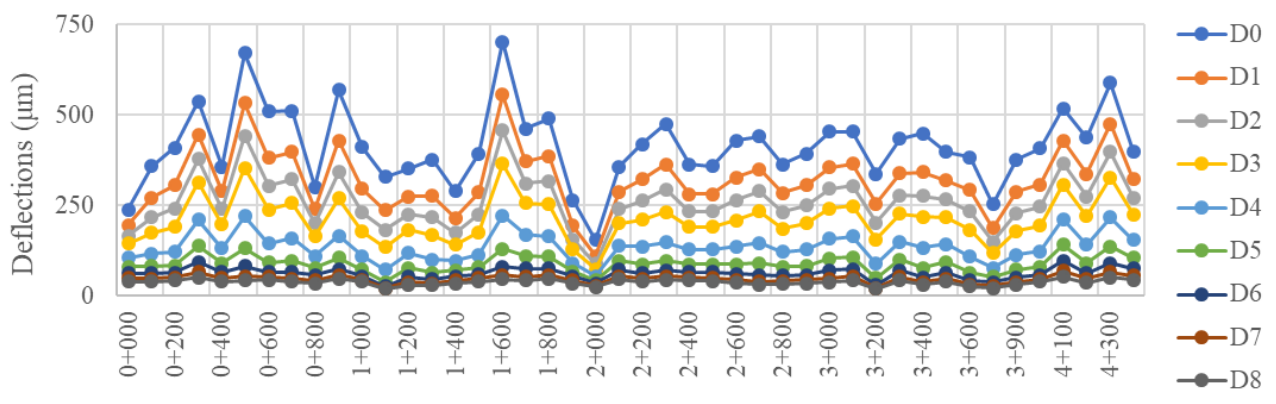

Distance (m)

Figure 2. FWD deflections in the West-East direction 


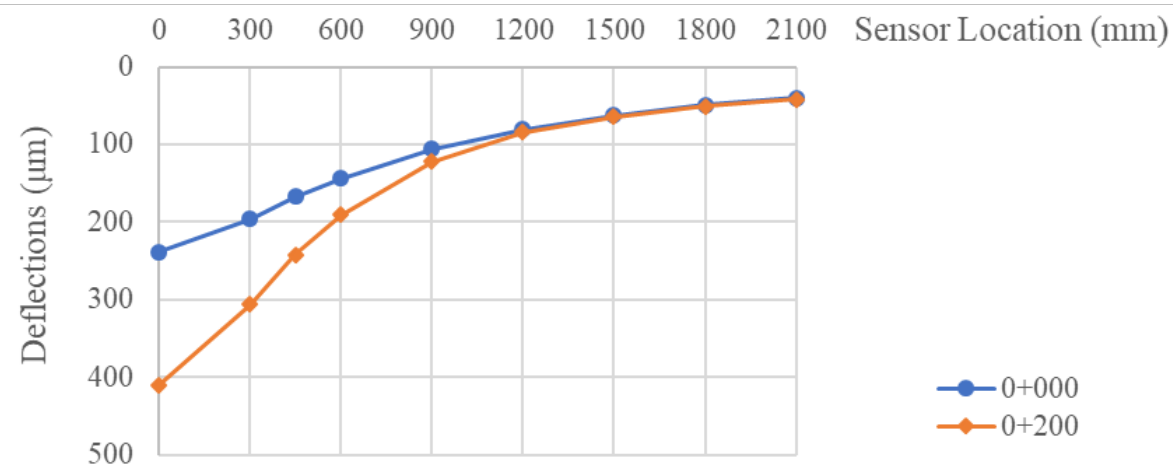

Figure 3. FWD deflection basins for pk $0+000$ and $0+200$

\subsection{GPR layer thickness measurements}

A GPR survey was carried out, at traffic speed, using a pair of $1.8 \mathrm{GHz}$ antennas, according to ASTM D4748-10 [11] (Figure 4). The tests were performed along the exterior wheel paths of the lanes.
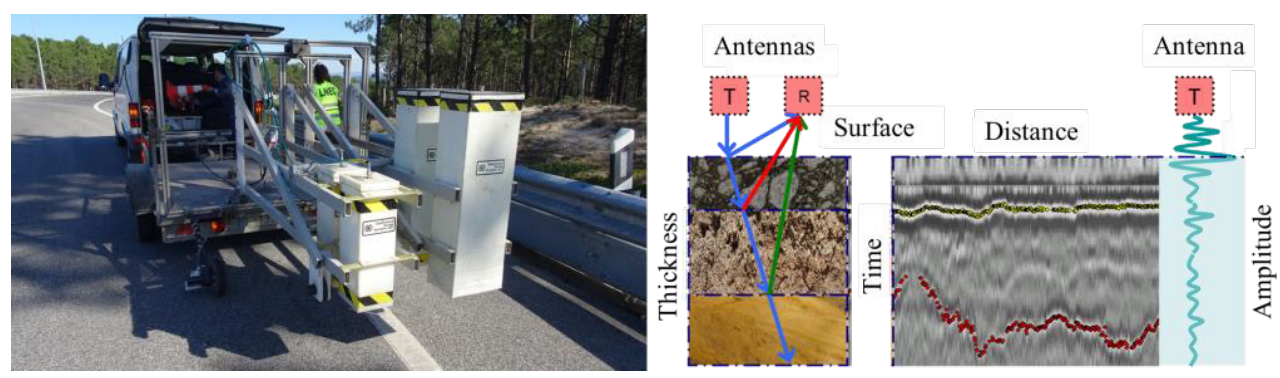

Figure 4. GPR antennas during the tests (left) and schematic representation of GPR test (right).

For each survey line, GPR data was recorded using three different antenna offsets, considering the following distances between the receiver and the transmitter antennas: $0.28 \mathrm{~m}, 0.69 \mathrm{~m}$ and $0.97 \mathrm{~m}, \mathrm{~A}, \mathrm{~B}$ and C configuration, respectively (Figure 5).

The GPR data collected were processed using the ReflexW software. Figure 6 presents an example of the B-scan measured along the external path in the West-East direction for each GPR offset configuration (see Figure 5).
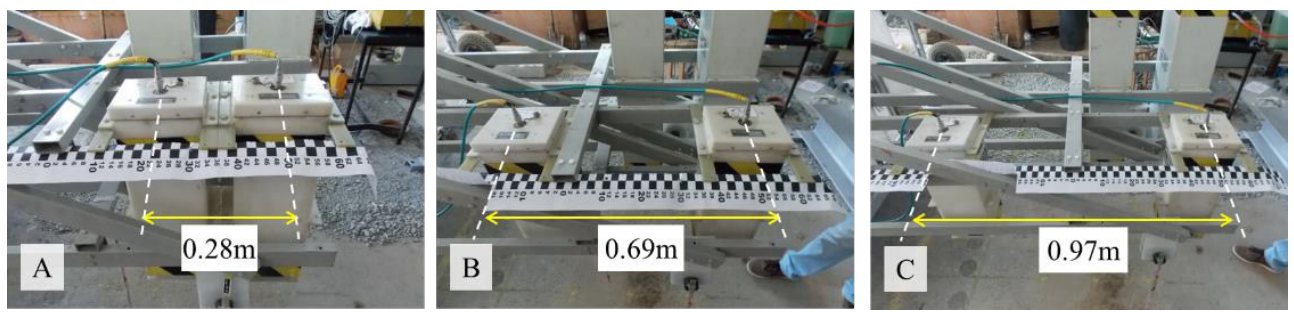

Figure 5. GPR offset configuration along survey lines 


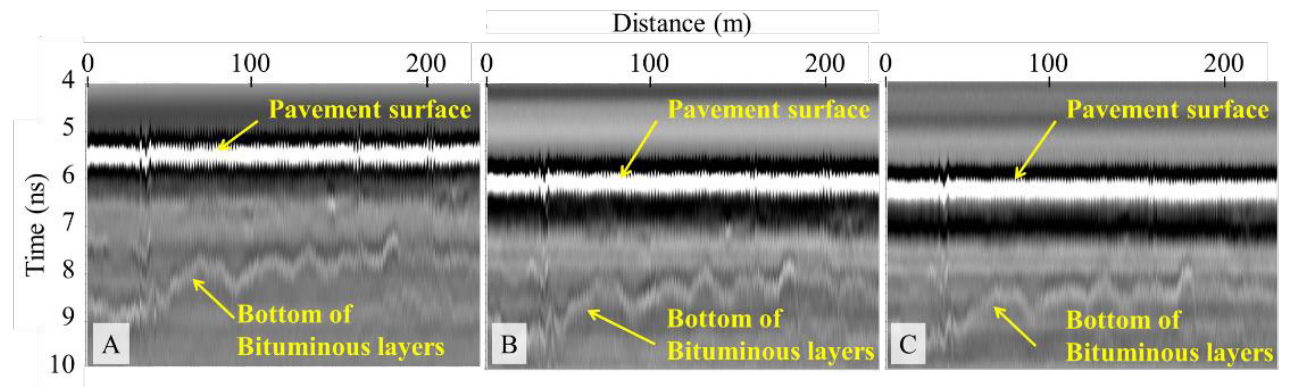

Figure 6. Example of the GPR measurements for A, B and C offset configurations.

The thickness of the bituminous layer was calculated combining the data from the different GPR offsets (A, B and C), based on the CMP-AC [9].

For each sample, the A-Scans from the different antenna offset configurations were merged and the correction of the start time of the signal was performed adapting the surface reflection wave to the velocity of the electromagnetic wave on the air, $0.3 \mathrm{~m} / \mathrm{ns}$ (Figure 7).

The velocity of the propagation of the wave in the bituminous layer (first layer) was determined using the CMP-velocity analysis from ReflexW applied to the merged corrected GPR data (Figure 7). The procedure consisted on the adjustment of the reflection varying the boundary and the velocity of the hyperbolas of the CMP-velocity analysis manual adaptation (Figure 8).

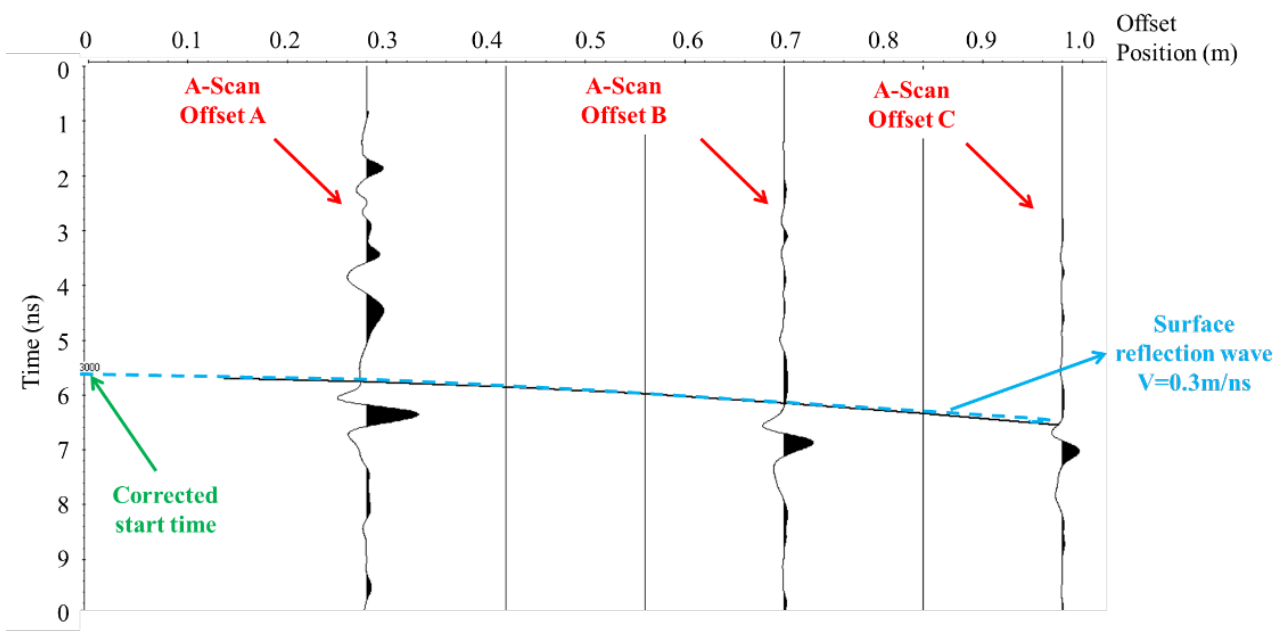

Figure 7. Example of CMP signal start time correction (pk 0+000) 


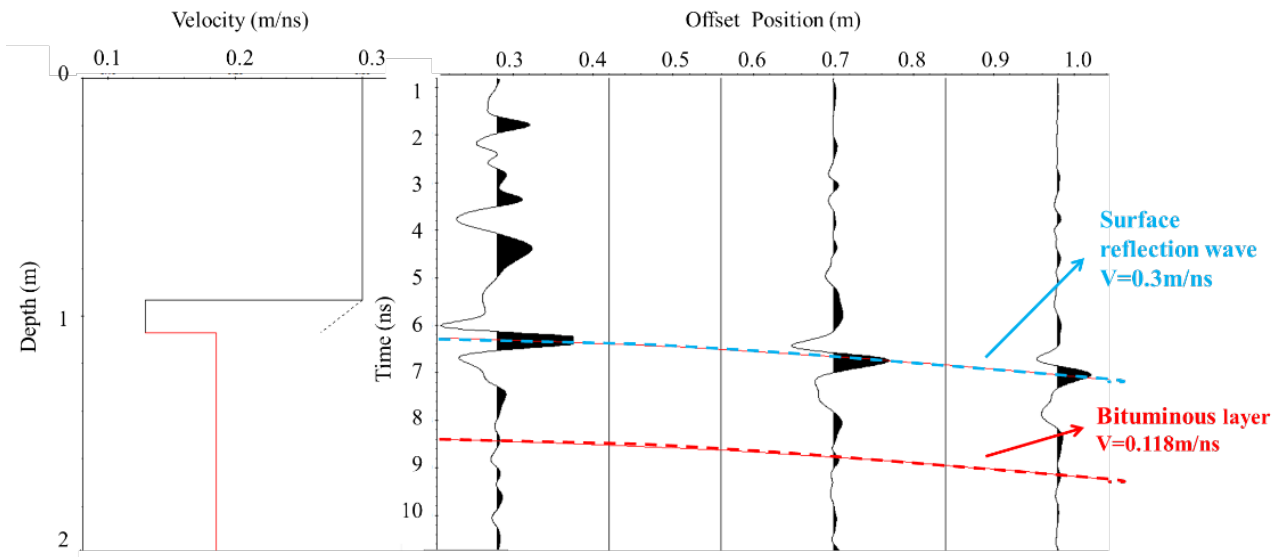

Figure 8. Example of CMP manual velocity analysis (pk $0+000)$

Knowing the velocity of the propagation of the wave in the bituminous layer (v), the dielectric value of the material $(\varepsilon)$ was calculated using Eq. (1). Table 1 shows the results of velocity, dielectric value and thickness for the bituminous layer, obtained from the CMP-AC, at the case study points (pk $0+000$ and pk $0+200$ ). The estimated thickness values are similar to the ones obtained using the Surface Reflection Method $(0.181 \mathrm{~m}$ and $0.128 \mathrm{~m}$ for pk $0+000$ and pk $0+200$, respectively).

$$
\mathrm{v} \cong \frac{\mathrm{c}}{\sqrt{\varepsilon}} ; \mathrm{c}=0.3 \mathrm{~m} / \mathrm{ns} \text { (speed of light in vacuum) }
$$

Table 1. Wave velocity, dielectric value and thickness obtained from CMP-AC

\begin{tabular}{|c|c|c|c|c|c|}
\hline Location & $\mathbf{h}_{\text {Design }}(\mathbf{m})$ & $\mathbf{t}(\mathbf{n s})$ & Velocity $(\mathbf{m} / \mathbf{n s})$ & $\boldsymbol{\varepsilon}$ & $\mathbf{h}_{\text {CMP-AC }}(\mathbf{m})$ \\
\hline $0+000$ & 0.125 & 3.154 & 0.118 & 6.5 & 0.186 \\
\hline $0+200$ & 0.125 & 2.041 & 0.129 & 5.4 & 0.132 \\
\hline
\end{tabular}

\subsection{Structural Evaluation}

For each point, back-calculation was performed using BISAR 3.0. In the pavement model, four layers were defined. The first layer corresponds to the bituminous layer, the second layer is the granular material layer while the third and fourth layers were used to model the foundation: an upper layer of $0.30 \mathrm{~m}$ thick over a semi-infinite layer.

Table 2. Pavement response models using design thickness

\begin{tabular}{|c|c|c|c|c|c|c|c|c|}
\hline \multirow{2}{*}{ Location } & \multirow{2}{*}{$\begin{array}{c}\text { Bituminous } \\
\text { thickness data }\end{array}$} & \multicolumn{3}{|c|}{ Bituminous layer } & \multicolumn{2}{c|}{ Granular layer } & \multicolumn{2}{c|}{ Foundation } \\
\cline { 3 - 9 } & $\mathbf{E}_{\mathbf{1}}(\mathbf{M P a})$ & $\mathbf{h}_{\mathbf{1}}(\mathbf{m})$ & $\mathbf{T e m p}_{\text {sup }}\left({ }^{\mathbf{O}} \mathbf{C}\right)$ & $\mathbf{E}_{\mathbf{2}}(\mathbf{M P a})$ & $\mathbf{h}_{\mathbf{2}}(\mathbf{m})$ & $\mathbf{E}_{\mathbf{3}}(\mathbf{M P a})$ & $\mathbf{E}_{\mathbf{4}}(\mathbf{M P a})$ \\
\hline \multirow{2}{*}{$0+000$} & Design & 10000 & 0.125 & 17.1 & 3000 & 0.200 & 100 & 220 \\
\cline { 2 - 9 } & GPR & 10000 & 0.186 & 17.1 & 1000 & 0.200 & 100 & 220 \\
\hline \multirow{2}{*}{$0+200$} & Design & 10000 & 0.125 & 16.3 & 300 & 0.200 & 100 & 200 \\
\cline { 2 - 9 } & GPR & 10000 & 0.132 & 16.3 & 300 & 0.200 & 100 & 200 \\
\hline
\end{tabular}

LEGEND: $\mathrm{E}_{\mathrm{i}}=$ elastic modulus of layer $\mathrm{i} ; \mathrm{h}_{\mathrm{i}}=$ thickness of layer $\mathrm{i}$ 
The elastic moduli of the layers were estimated based on the results of the FWD load tests, following the methodology usually applied in bearing capacity evaluation of pavements [1]. The validation criteria was the Root Mean Square Deviation Error that was always below $2.4 \%$ for all the points analysed. Table 2 presents the pavement response models for each point, estimated using both the design data and the estimated thickness of the bituminous layers from the GPR measurements.

\section{Final considerations}

Two NDT methods were combined to assess the bearing capacity of a flexible pavement: FWD and GPR. Pavement deflections were measured with FWD and the layer thickness was estimated with GPR. For this study the bituminous layer thickness was estimated based on a coreless method developed by the authors: CMP-AC [9]. This approach combined multiple GPR offset configurations to estimate the velocity wave propagation in the bituminous layer.

The results show that the pavement response models depend on the accuracy of the bituminous layer thickness. For pk $0+000$, a 30\% difference between the design and the estimated bituminous layer thickness lead to an overestimation of the granular layer moduli ( 3 times higher). Moreover, the value obtained for the granular layer moduli, when using the design thickness $(3000 \mathrm{MPa})$, is not a typical value for unbound layers.

The authors wish to acknowledge the financial support of Fundação para a Ciência e Tecnologia (FCT) for funding the Ph.D. Grant SFRH/BD/110319/2015. The authors would also like to thanks Universidade de Vigo and the National Laboratory for Civil Engineering for supporting this research.

\section{References}

[1] S. Fontul, Structural evaluation of flexible pavements using non-destructive tests $[\mathrm{PhD}$ Thesis], Universidade de Coimbra (2004).

[2] J. Domitrović, T. Rukavina, Rom. J. Transp. Infrastruct. 2 11-21 (2013).

[3] A. Noureldin, K. Zhu, S. Li, D. Harris, Transp. Res. Rec. J. Transp. Res. Board. 1860, 90-99 (2003).

[4] P.L.H. Irwin, D. Ph, Backcalculation: an overview and perspective, in: FWD / Backcalc. Work. 3 - BCRRA 2002, 24-26 (2002)

[5] I.L. AL-Qadi, S. Lahouar, Constr. Build. Mater. 19, 763-772 (2005)

[6] R.M. Morey, T.R. Board, NCHRP Synthesis 255, Ground Penetrating Radar for Evaluating Subsurface Conditions for Transportation Facilities, NAP (1998)

[7] H.M. Jol, Ground penetrating radar: theory and applications, Elsevier (2009)

[8] D.J. Daniels, Ground penetrating radar, 2nd Editio, IEE (2004).

[9] V. Marecos; S. Fontul; M. Solla and M.L. Antunes, Measurements. 128, 295-305 (2018)

[10] ASTM D4695, Standard Guide for General Pavement Deflection Measurements, in: Vol. 04.03 Road Paving Mater (2003)

[11]ASTM D4748-10, Standard Test Method for Determining the Thickness of Bound Pavement Layers (2015). 